\title{
Using Co-Precipitation Method Determining Synthesis and Characterization of Fe Doped Zinc Oxide Nanoparticles
}

\author{
S. Bharanidharan, K. Sathiyamurthy, B. Sheeba
}

\begin{abstract}
In through concoction co-precipitation strategy using ferric nitrate, zinc nitrate and sodium hydroxide in fluid arrangements, orchestrate and portrayal of Fe doped $\mathrm{ZnO}$ nanoparticles were prepared in the present work. X-beam diffraction has confirmed the growth of $\mathrm{Fe}$ doped $\mathrm{ZnO}$ from the precursor. This result has revealed that nanoparticles have integrated excellent crystalline forces in nature. SEM investigations show that $\mathrm{ZnO}$ nanoparticles have been doped by the round and minimally agglomerated Fe. Room temperature powerless ferromagnetism, distinctive in the appealing characteristics of $\mathrm{Fe}$ doped $\mathrm{ZnO}$ powderKeywords in relation to room temperature: zinc oxide, SEM, chemical precipitation, $X R D, V S M$
\end{abstract}

Keywords : Nano particles, ZnO, Ferro Magnetism

\section{INTRODUCTION}

As a result of its property of showing room temperature ferromagnetism, advance metal (TM)- doped $\mathrm{ZnO}$ has significantly considered. $\mathrm{ZnO}$ is one of the most significant oxide materials because of its extraordinary features and wide scope of precisely significant applications [1]. $\mathrm{ZnO}$ has a spot with the once-over of most promising plausibility for spintronics applications in light of its agreeable nature and moreover because of its potential as a sensible optoelectronic with a wide bandgap $(3.3 \mathrm{eV})$ and high exciton limiting imperativeness of 60 meV[ 2]. Among advancement metals, $\mathrm{Fe}$ has been extensively used as a dopant in the $\mathrm{ZnO}$ system. Fe-doped $\mathrm{ZnQ}$ is the material for research because of its properties like room temperature ferromagnetism, optical bandgap assortments and moreover antibacterial applications.

\section{EXPERIMENTAL METHOD}

\section{A. Material preparation}

To join of $\mathrm{Fe}$ doped $\mathrm{ZnO}$ nanoparticles, the going with materials were used. All the china used in this exploratory work was destructive washed. The compound reagents used were insightful reagent evaluation moving along with no more disinfection. Ultrapure water was used for all debilitating and test plan. $\mathrm{Fe}(\mathrm{NO} 3) 3.9 \mathrm{H} 2 \mathrm{O}$, $\mathrm{Zn}(\mathrm{NO} 3) 2.6 \mathrm{H} 2 \mathrm{O}$ and Sodium hydroxide $(\mathrm{NaOH})$, $\mathrm{CH} 3$ )2CO, methanol and ethanol were gained from s-d fine Chem. Ltd. independently. All of the manufactured mixes are above $98 \%$ virtue. Synthesis of $\mathrm{Fe}$ doped $\mathrm{ZnO}$ nanoparticles [1],[3],[5]

Nanocrystalline $\mathrm{Fe}$ doped $\mathrm{ZnO}$ powders are incorporated by utilizing substance compound co-precipitation [25],[27],[29]technique Essential measure of $\mathrm{Zn}(\mathrm{NO} 3) 2.6 \mathrm{H} 2 \mathrm{O}$ and $\mathrm{Fe}(\mathrm{NO} 3) 3.9 \mathrm{H} 2 \mathrm{O}$ are broken up in refined water contingent upon the level of Fe-doping arrangement were permitted to blend very well for 25-30 minutes at $80^{\circ} \mathrm{C}$. Next, suitable measure of $\mathrm{NaOH}$ arrangement was added drop by drop to the above arrangement. Promptly the white encourage was showed up. The encourage was gathered from the arrangement by including a known volume of CH3)2CO. Quick flocculation of nanoparticles was happened. To expel the last hints of followed contaminations, the particles were washed thrice utilizing de-ionized water, ethanol and $\mathrm{CH} 3$ )2CO. The washed particles were dried at $80^{\circ} \mathrm{C}$ in air for 2h.Characterization method [2 ],[4],[6]

The integrated examples were described by embracing distinctive physico synthetic strategies explicitly. [26],[28],[30]The as-combined $\mathrm{Fe}$ doped $\mathrm{ZnO}$ tests were portrayed utilizing the powder X-Ray diffraction estimation, which was done at room temperature by utilizing PW3040/60 XPERT-PRO prefix X-Ray diffractometer with monochromatized Cuk $\alpha$ radiation $(\lambda=1.54056 \AA)$. The surface morphology of the integrated examples has been done by the FEI Quanta FEG 200 Scanning Electron Microscope. The attractive estimations of the incorporated examples were taken by a vibrating test magnetometer model lakeshore-7404 VSM 155 at room temperature. [7],[9],[11]

\section{RESULTS AND DISCUSSION}

\section{A. Structural analysis}

It is realized that line expanding of diffraction pinnacles is impacted by the crystallite measure and the inward strains[31],[33],[35]. Different rates of doping materials is appeared in Fig1, which obviously uncovers that the expanded grain development of the example during the higher amount of doping materials. [20],[ 22], [24]
Revised Manuscript Received on July 22, 2019.

Dr. S. Bharanidharan, Department of physics, Bharath Institute of Higher education and research, Chennai , India. Email: bharani.dharan0@ gmail.com

K. Sathiyamurthy, Department of physics, Bharath Institute of Higher education and research, Chennai , India. Email: gksathiya0806@gmail.com

B. Sheeba , Department of physics, Bharath Institute of Higher education and research, Chennai, India. Email: bsheeba1@gmail.com 


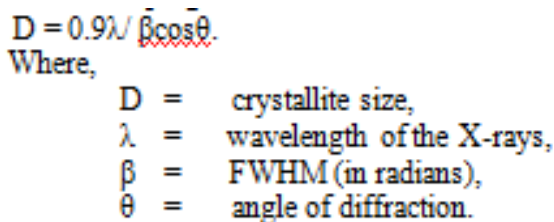

The size got from Scherrer's recipe yields the evident or normal crystallite sizes of the blended [32],[34] examples are determined to be $17,20,24,25,32$ and $22 \mathrm{~nm}$ for $0.01,0.02$, $0.03,0.04,0.05$, and 0.06 utilized for arrangement of various molar proportion in $\mathrm{Fe}$ doped $\mathrm{ZnO}$ nanoparticles, separately. [8],[10],[12]

\section{B. Scanning Electron Microscopy (SEM)}

Fig. 2 shows, the detailed morphology of the hexagonal, from which dispersed, spherical and little agglomerated Fe doped $\mathrm{ZnO}$ nanoparticles were clearly observed for the prepared samples by using 0.04 respectively. [13], [15] ,[17]

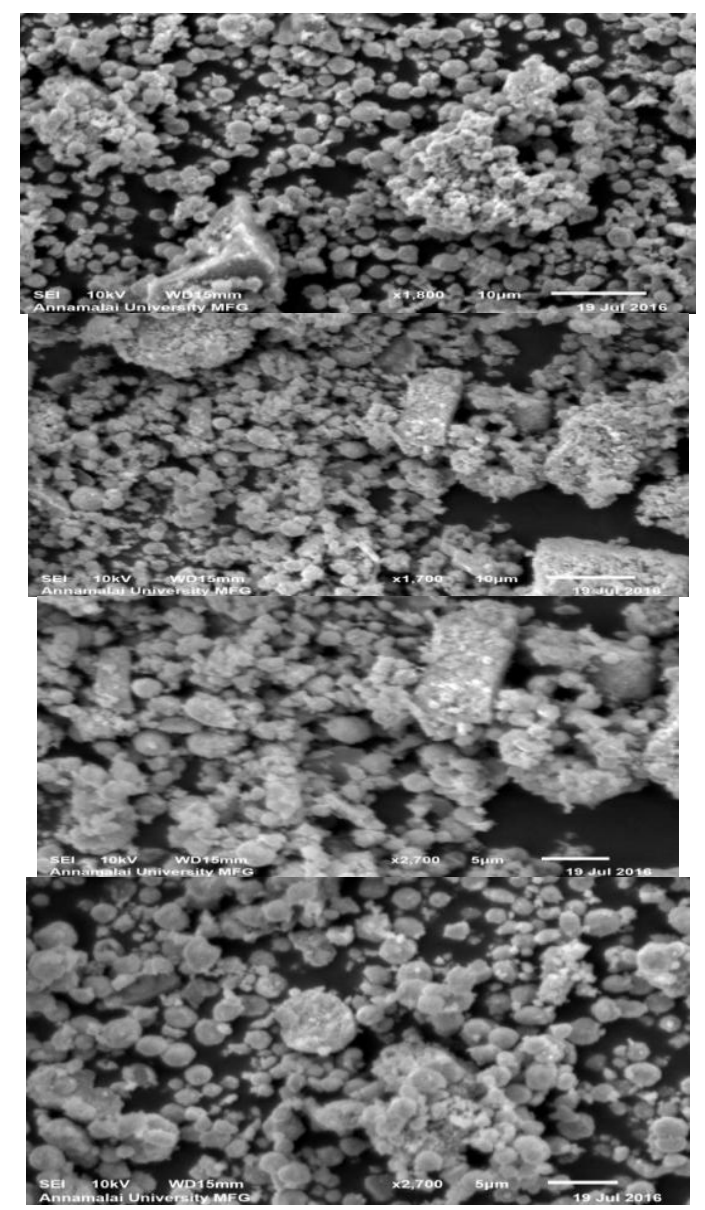

Figure 2 SEM images of Fe doped $\mathrm{ZnO}$ nanoparticles

Vibrating test magnetometer (VSM) is utilized to decide the charge of the examples integrated. At the point when an attractive material is set in a uniform attractive field, a dipole minute is actuated which is relative to the vulnerability of the example and the connected field. On the off chance that the example is vibrated occasionally, at that point it can actuate an electrical sign in a pickup curl. The situation of the pickup curl is balanced so as to give the most extreme acceptance absent much clamor.

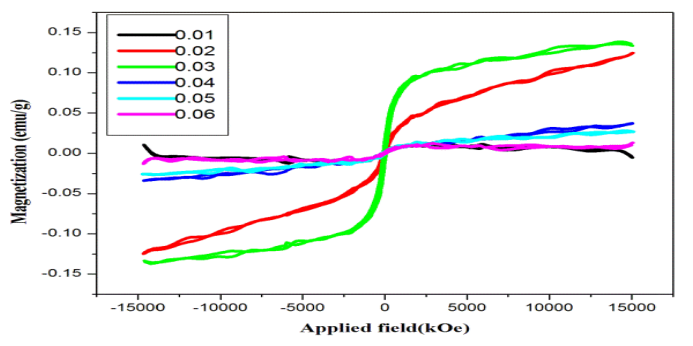

Fig.4 Room temperature magnetic studies of Fe doped ZnO nanoparticles

In the present work manages the combination, basic, size, morphology and attractive properties of unadulterated and $\mathrm{Fe}$ doped $\mathrm{ZnO}$ nanoparticles by utilizing co-precipitation strategy. The molecule sizes of the $\mathrm{Fe}$ doped $\mathrm{ZnO}$ nanocrystallites blended with different rates like $(0.01,0.02$, $0.03,0.04,0.05,0.06$ and 0.07 ) were $17,20,24,25,32$ and $22 \mathrm{~nm}$ individually. It was discovered that the doping rates of amount assumed significant jobs in the molecule size impact of the nanocrystalline $\mathrm{Fe}$ doped $\mathrm{ZnO}$ nanoparticles. The round like morphologies were watched for Fe doped $\mathrm{ZnO}$ nanoparticles arranged with various rates $0.01,0.02,0.03$, $0.04,0.05,0.06$ and 0.07 . Also, the agglomeration impact was expanding with expanding doping rates amount. It very well may be seen that the every one of the examples displays the too paramagnetic conduct of $\mathrm{Fe}$ doped $\mathrm{ZnO}$ nanoparticles. It has been discovered that the varieties of doping rates significantly affect the size and attractive properties of $\mathrm{Fe}$ doped $\mathrm{ZnO}$ nanoparticles. The readied $\mathrm{Fe}$ doped $\mathrm{ZnO}$ nanoparticles show applications in the regions of nano gadgets, sensors, batteries and photocatalysis. [19],[21],[23]

Table 1: Crystallite size D (nm) and Saturation magnetization $\left(\mathrm{M}_{\mathrm{s}}\right)$ of Fe doped $\mathrm{ZnO}$ nanoparticles

\begin{tabular}{|c|c|c|c|}
\hline \multicolumn{5}{|c|}{ Fe doped $\mathrm{ZnO}$} \\
\hline Ratios & $\begin{array}{c}\text { Crystallite } \\
\text { size (D) }\end{array}$ & $\begin{array}{c}\mathrm{Ms} \\
(\mathrm{emu} / \mathrm{g})\end{array}$ & $\begin{array}{c}\text { Coercivity } \\
\text { (Oe) }\end{array}$ \\
\hline 0.01 & 17 & 0.72 & 90.3 \\
\hline 0.02 & 20 & 0.79 & 72.7 \\
\hline 0.03 & 24 & 0.82 & 51.4 \\
\hline 0.04 & 25 & 0.91 & 24.1 \\
\hline 0.05 & 32 & 1.74 & 0.9 \\
\hline 0.06 & 22 & 0.85 & 63.5 \\
\hline
\end{tabular}

\section{CONCLUSION}

In the present work deals with the association, assistant, size, morphology and alluring properties of unadulterated and Fe doped ZnO namoparticles by using co-precipitation procedure. The particle sizes of the Fe doped ZnO namocrystallites fused with various rates like $(0.01,0.02,0.03,0.04,0.05,0.06$ and 0.07$)$ were 17,20 , $24,25,32$ and $22 \mathrm{~nm}$ independently. It was found that the doping rates of sum expected noteworthy occupations in the particle size effect of the nanocrystaline Fe doped $\mathrm{ZnO}$ nanoparticles. The roundabout like morphologies were looked for $\mathrm{Fe}$ doped $\mathrm{ZnO}$ nanoparticles masterminded with differ ent rates $0.01,0.02,0.03,0.04$, $0.05,0.06$ and 0.07 . Moreover, the agglomeration effect was extending with growing doping rates sum. It might be seen that the all of the models demonstrates the too paramagnetic direct or Fe doped $\mathrm{Kn}$ nanoparticles. It has been found that the assortments of doping rates fe or Fe doped zol anoped 


\section{REFERENCES}

1. Nageshwari M., Jayaprakash P., Kumari C.R.T., Vinitha G., Caroline M.L., Growth, spectral, linear and nonlinear optical characteristics of an efficient semiorganic acentric crystal: L-valinium L-valine chloride, 2017, Physica B: Condensed Matter, V-511, PP -1-9,

2. Sangeetha P., Jayaprakash P., Nageshwari M., Rathika Thaya Kumari C., Sudha S., Prakash M., Vinitha G., Lydia Caroline M., Growth and characterization of an efficient new NLO single crystal L-phenylalanine D-methionine for frequency conversion and optoelectronic applications, 2017, Physica B: Condensed Matter, V-525, PP-164-174

3. Peer Mohamed M., Jayaprakash P., Nageshwari M., Rathika Thaya Kumari C., Sangeetha P., Sudha S., Mani G., Lydia Caroline M., Crystal growth, structural, spectral, thermal, linear and nonlinear optical characterization of a new organic nonlinear chiral compound L-tryptophan-fumaric acid-water (1/1/1) suitable for laser frequency conversion, 2017, Journal of Molecular Structure, V-1141, PP-551-562

4. Jayaprakash P., Sangeetha P., Kumari C.R.T., Caroline M.L., Investigation on the growth, spectral, lifetime, mechanical analysis and third-order nonlinear optical studies of L-methionine admixtured D-mandelic acid single crystal: A promising material for nonlinear optical applications, 2017, Physica B: Condensed Matter, V-518, PP-1-12

5. Nageshwari M., Kumari C.R.T., Vinitha G., Mohamed M.P., Sudha S., Caroline M.L., Crystal growth, structural, spectral, thermal, dielectric, linear and nonlinear optical characteristics of a new organic acentric material: L-Methionine-Succinic acid (2/1), 2018, Journal of Molecular Structure, V-1155, PP-101-109

6. Jayaprakash P., Sangeetha P., Kumari C.R.T., Baskaran I., Caroline M.L., Growth and characterization of 1-asparagine monohydrate admixtured dl-mandelic acid nonlinear optical single crystal, 2017, Journal of Materials Science: Materials in Electronics, V-28, PP-18787-18794

7. Rathika Thaya Kumari C., Nageshwari M., Jayaprakash P., Sangeetha P., Sudha S., Lydia Caroline M., Investigation on growth, optical, thermal, mechanical, dielectric, LDT studies of sulphanilic acid monohydrate: A promising third-order nonlinear optical material, 2017, Journal of Nonlinear Optical Physics and Materials, V-26, I - 2,

8. Thaya Kumari C.R., Nageshwari M., Raman R.G., Caroline M.L., Crystal growth, spectroscopic, DFT computational and third harmonic generation studies of nicotinic acid, 2018, Journal of Molecular Structure, V-1163, PP-137-146

9. Nageshwari M., Kumari C.R.T., Sangeetha P., Vinitha G., Caroline M.L., Third order nonlinear optical, spectral, dielectric, laser damage threshold, and photo luminescence characteristics of an efficacious semiorganic acentric crystal: L-Ornithine monohydrochloride, 2018, Chinese Journal of Physics, V-56, I - 2, PP-502-519

10. Kumari C.R.T., Jayaprakash P., Nageshwari M., Mohamed M.P., Sangeetha P., Caroline M.L., Growth, optical, photoluminescence, dielectric, second and third order nonlinear optical studies of benzoyl valine acentric crystal, 2017, Molecular Crystals and Liquid Crystals, V-658,I - 1, PP-186-197

11. Rathika Thaya Kumari C., Nageshwari M., Sudha S., Lydia Caroline M., Mani G., Influence of uranyl on the growth, linear, laser damage threshold and nonlinear optical studies on potential nonlinear optical single crystal: L-Alanine, 2015, Journal of Chemical and Pharmaceutical Sciences, V-2015-October,PP-166-170,

12. Rathika Thaya Kumari C., The detailed study ontwo dimensional hydrogen atom, 2013, Middle - East Journal of Scientific Research, V-17,I-12, PP-1900-1902

13. Rathika Thaya Kumari C., Theoretical study about the measurement of ultrasonic velocity using different methods, 2013, Middle - East Journal of Scientific Research, V-17, PP-12-

14. Mukunthan A., Rathika Thaya Kumari C., Nageshwari M., Prakash D., The effect of super saturation and crystal growth kinetics of L-arginine per chlorate, 2013, Middle - East Journal of Scientific Research, V-17,I-12 PP-1825-1827

15. Sree Latha R., Vijayaraj R., Azhagiya Singam E.R., Chitra K., Subramanian V., 3D-QSAR and Docking Studies on the HEPT Derivatives of HIV-1 Reverse Transcriptase, 2011, Chemical Biology and Drug Design, V-78,I-12, PP-1816-1819

16. Sree Latha R., Vijayaraj R., Padmanabhan J., Azhagiya Singam E.R., Chitra K., Subramanian V., 3D-QSAR studies on the biological activity of juvenile hormone mimetic compounds for Culex pipiens Larvae, 2013, Medicinal Chemistry Research, V-22, I-12,PP-418-426

17. Subashini G.,A simple proof on coloring of dominated special graphs, Indian Journal of Science and Technology,V-7,I-,PP-5-6,Y-2014

18. Ramya N.,On coloring of corona graphs, Indian Journal of Science and Technology,V-7,I-SUPPL2,PP-9-11,Y-2014.

19. Ramya N., On colourings of wheel graph (Wn), Indian Journal of Science and Technology,V-7,I-,PP-72-73,Y-2014.
20. Ramya N., On star chromatic number of P3 (n), Indian Journal of Science and Technology,V-7,I-,PP-7-8,Y-2014.

21. Vijayaragavan S.P.,An investigative expert that's general FBG sensors,International Journal of Mechanical Engineering and Technology,V-8,I-8,PP-1500-1505,Y-2017

22. Vijayaragavan S.P.,Equalization routing protocol for Wi-Fi sensor strategy,International Journal of Mechanical Engineering and Technology,V-8,I-8,PP-1662-1666,Y-2017

23. Karthik B., Kiran Kumar T.V.U., Vijayaragavan P., Bharath Kumaran E.,Design of a digital PLL using 0.35 1̂1/4m CMOS technology,Middle East Journal of Scientific Research,V-18,I-12,PP-1803-1806,Y-2013

24. Kanniga E., Selvaramarathnam K., Sundararajan M.,Kandigital bike operating system,Middle - East Journal of Scientific Research,V

25. Jasmin M., Vigneshwaran T., Beulah Hemalatha S.,Design of power aware on chip embedded memory based FSM encoding in FPGA,International Journal of Applied Engineering Research,V-10,I-2,PP-4487-4496,Y-2015

26. Jasmin M.,Optimization techniques for low power VLSI circuits,Middle - East Journal of Scientific Research,V-20,I-9,PP-1082-1087,Y-2014

27. Jasmin M., Vigneswaran T.,Fuzzy controller for error control of on Chip communication,2017 International Conference on Algorithms, Methodology, Models and Applications in Emerging Technologies, ICAMMAET 2017,V-2017-January,I-,PP-1-5,Y-2017

28. Ramya N., On star chromatic number of P3 (n), Indian Journal of Science and Technology,V-7,I-,PP-7-8,Y-2014.

29. Cauchy Multiplication of Euler Summable series in Ultrametric Fields, PNNVS R.Deepa Commentationes Mathematicae 53 ((1)), 73- 79

30. Kumaravel A., Meetei O.N.,An application of non-uniform cellular automata for efficient cryptography,Indian Journal of Science and Technology,V-6,I-SUPPL5,PP-4560-4566,Y-2013

31. Kumaravel A., Meetei O.N.,An application of non-uniform cellular automata for efficient cryptography,2013 IEEE Conference on Information and Communication Technologies, ICT 2013,V-,I-,PP-1200-1205,Y-2013

32. Kumarave A., Rangarajan K.,Routing alogrithm over semi-regular tessellations,2013 IEEE Conference on Information and Communication Technologies, ICT 2013,V-,I-,PP-1180-1184,Y-2013

33. Gopinath S., Sundararaj M., Elangovan S., Rathakrishnan E.,Mixing characteristics of elliptical and rectangular subsonic jets with swirling co-flow,International Journal of Turbo and Jet Engines,V-32,I-1,PP-73-83,Y-2015

34. Rathika Thaya Kumari C., A brief review on the impacts of tropospheric ozone on biological systems, 2013, Middle - East Journal of Scientific Research, V-17,I-12, PP-1820-1824

35. Mukunthan A., Rathika Thaya Kumari C., Nageshwari M., Prakash D., A brief review on the applications of fluorescent spectroscopy in biomedical diagnosis, 2013, Middle - East Journal of Scientific Research, V-17,I-12, PP-1828-1830

\section{AUTHORS PROFILE}

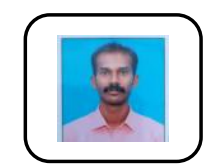

Dr. S. Bharanidharan, Associate Professor, Department of Physics, Bharath Institute of Higher Education and Research, Chennai, India

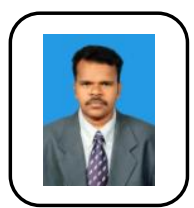

K. Sathiyamurthy Assistant Professor, Department of Physics, Bharath Institute of Higher Education and Research, Chennai, India

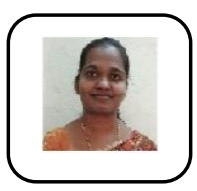

B. Sheeba profile which contains their education details, their publications, research work, membership, achievements, with photo that will be maximum 200-400 words. 